\title{
Frequency Dependence of the Suppressive Effects of Vibration on Atherosclerosis in the Rabbit
}

\author{
MARIKO OKI, TATSUYA ISHITAKE, AKI OHKUBO \\ AND TSUNETAKA MATOBA \\ Department of Environmental Medicine, Kurume University School of Medicine, \\ Kurume, 830 Japan
}

Received for publication October 25, 1989

\begin{abstract}
Summary: Whole-body vibration suppresses the development of atherosclerosis in the rabbit (Oki and Matoba, 1987). The present study was designed to clarify whether the effect of vibration on atherosclerosis depends on the frequency of vibration. Longitudinal vibrations at a frequency of 30 or $60 \mathrm{~Hz}$ was applied to 12 New Zealand white rabbits for 12 weeks. The gradual decrease in body weight and blood hematocrit in the vibration groups with time were parallel to the changes in the controls. The rate of increase in serum lipid concentrations induced by a cholesterol-rich diet was significantly suppressed in the vibration groups, as compared to the controls. This may be due to the vibration and not the diet. The aortic wall was thinner at $60 \mathrm{~Hz}$ than at $30 \mathrm{~Hz}$, whereas the ratios of trace metals $(\mathrm{Ca} / \mathrm{Mg}$ and $\mathrm{Zn} / \mathrm{Cu})$ in the aortic tissues were smaller at $30 \mathrm{~Hz}$. The area of plaque formation in the intima was smaller at $60 \mathrm{~Hz}$ than at $30 \mathrm{~Hz}(\mathbf{p}<0.05)$. Thus, the suppressive effect of vibration on the development of atherosclerosis in the aorta may be greater at a frequency of $60 \mathrm{~Hz}$ than at $30 \mathrm{~Hz}$. Vibration may play an important role in lipid metabolism.
\end{abstract}

Key words: whole-body vibration - atherosclerosis - metal concentrations vibration frequency - plaque formation

\section{Introduction}

The effects of whole-body vibration on the organs and tissues of humans and animals may depend on the frequency of the vibration (Ljung and Sivertsson, 1975; Hudlicka and Wright, 1978; Matoba and Chiba, 1989). In previous experiments, whole-body vibration suppressed the development of atherosclerosis in rabbits on a cholesterol-rich diet and also reduced the rate of increase in serum lipid concentrations (Oki and Matoba, 1987). The present study was designed to clarify the relationship between the vibration frequency and the suppressive effect of vi- bration on the development of atherosclerosis in the rabbits.

\section{Materials and Methods}

Seventeen male New Zealand white rabbits, weighing an average of $2.3 \mathrm{~kg}$, were arranged in order of body weight and divided into 3 groups: group A consisted of 6 rabbits exposed to vibrations of $30 \mathrm{~Hz}$. Group B consisted of 6 rabbits exposed to vibrations of $60 \mathrm{~Hz}$, and the others were controls (Group C). All the rabbits were fed $100 \mathrm{~g}$ of $1 \%$ cholesterol in their diet per day for 12 weeks. The com- 
position of metals per $100 \mathrm{~g}$ of food was $1,640 \mathrm{mg}$ of calcium $(\mathrm{Ca}), 240 \mathrm{mg}$ of mag nesium $(\mathrm{Mg}), 4.06 \mathrm{mg}$ of zinc $(\mathrm{Zn})$ and $1.13 \mathrm{mg}$ of copper $(\mathrm{Cu})$. Each rabbit in groups $\mathrm{A}$ and $\mathrm{B}$ was placed in a cage that was mounted on the platform of a vibrator (Akashi Seisakusho Co.; ASE-385). Longitudinal vibrations with an acceleration level of $10 \mathrm{~m} / \mathrm{s}^{2}$ at each frequency were administered, every other day for $30 \mathrm{~min}$ utes, over a period of 12 weeks. The noise generated by the vibrator was approximately $68 \mathrm{~dB}$ inside and $58 \mathrm{~dB}$ outside the cage. To avoid the bias of noise, the control rabbits were placed in a cage close to the operating vibrator.

The following parameters were observed. Body weight was measured every week. Hematocrit, serum total cholesterol (TC), serum triglycerides (TG), and serum $\mathrm{Ca}, \mathrm{Mg}, \mathrm{Zn}$ and $\mathrm{Cu}$ were measured every 4 weeks. Blood samples were obtained from auricular veins, 12 hours after fasting; and the sera were stored at $-85^{\circ} \mathrm{C}$. Serum metals were measured by ashing with nitric acid and perchloric acid. The ash was dissolved by adding $1 \mathrm{~N} \mathrm{HCl}$ and $0.5 \%$ lanthanum chloride by weight. The metal concentrations were determined with an atomic absorption/flame emission spectrophotometer (Shimazu Co.; AA 64012). After 12 weeks of experiments, all the rabbits were intravenously anesthetized with sodium pentobarbital (Nembutal ${ }^{\circledR}: 35-45 \mathrm{mg} / \mathrm{kg}$ ), and the aortas were rapidly removed and frozen with liquid nitrogen. For light microscopic examination, a part of each aorta was fixed in $10 \%$ formalin and embedded in paraffin for staining with Hematoxylin-Eosin and Elastica-Van Gieson methods. Histologically, the ratios of intima (I) to I plus media (M), I/I + M, were calculated at the maximal and minimal wall thickness sites from about 30 measurements at each site. The area of plaque formation in the intima was analyzed with an image analysing system (Cosmozone 98; Nikon). The metal concentrations in the aortic tissues were measured by the same methods that were used for the serum samples.

\section{Results}

1. Body weight, hematocrit, serum total cholesterol and triglycerides.

Table 1 shows the changes in body weight, hematocrit, serum total cholesterol (TC) and serum triglycerides (TG) induced by vibration. The body weights in all groups increased approximately 15\% after 12 weeks. No significant differences among the 3 groups were observed in the rate of increase in body weight after each week. Significant food refusals were not encountered during the experimental period. The hematocrit for each group averaged approximately $42 \%$ at the beginning of the experiment. The values decreased gradually with time to $29.2 \%, 28.8 \%$ and $27.3 \%$ for groups $\mathrm{A}, \mathrm{B}$ and $\mathrm{C}$, respectively, by the 8 th week. No significant differences were noted between the 3 groups. Thereafter, the hematocrit increased slightly to approximately $31 \%$ in each group by the 12 th week.

The mean value for $\mathrm{TC}$ in the controls increased markedly from $42.7 \mathrm{mg} / \mathrm{dl}$ to 1274, which is about 30 times the basal level, following the $1 \%$ cholesterol diet. The rates of increase of $\mathrm{TC}$ in groups $\mathrm{A}$ and $\mathrm{B}$ were much less. The mean values of TC in groups A and B increased from 31.8 to $652 \mathrm{mg} / \mathrm{dl}$ and from 23.4 to $560 \mathrm{mg} /$ $\mathrm{dl}$, respectively. There was a significant difference between the values before and after the experimental period in each group. The TG in the controls doubled by the end of the experiments, whereas the TG in groups $\mathrm{A}$ and $\mathrm{B}$ were reduced by the vibration.

\section{Histological findings.}

An abundant plaque formation on the intimal surface was observed in the as- 
cending aorta in all groups. In the descending aorta, however, the degrees of plaque formation were much different for each group. The areas of plaque formation in ascending and descending thoracic aortas in groups A, B and C were 20.05 \pm
2.09 (mean $\pm \mathrm{SE}$ ) \%, $13.38 \pm 8.28 \%$ and $30.86 \pm 11.32 \%$, respectively. A significant difference was noted between the areas in group A and group B $(\mathrm{p}<0.05)$. Histologically, the thickness of the intima (I) and media $(M)$ in the thoracic aorta was

TABLE 1

Body weight, hematocrit, serum total cholesterol and triglycerides in each group before and after the experiments

\begin{tabular}{|c|c|c|c|c|}
\hline & Group A & Group B & Gro & up $\mathrm{C}$ \\
\hline \multicolumn{5}{|l|}{ Body weight $(\mathrm{kg})$ : } \\
\hline Before & $2.29 \pm 0.04 \neg$ & $2.36 \pm 0.07 \neg$ & $2.31 \pm$ & $=0.06 \neg$ \\
\hline 12 wks after & $2.63 \pm 0.05^{*}{ }^{*}$ & $2.69 \pm 0.04-^{*}$ & $2.76 \pm$ & : \\
\hline \multicolumn{5}{|l|}{ Hematocrit (\%): } \\
\hline Before & $41.9 \pm 0.7 \neg$ & $41.6 \pm 0.7 \neg$ & $41.6 \pm$ & $=0.8 \neg$ \\
\hline 12 wks after & $32.8 \pm 0.9-$ & $31.0 \pm 0.9-\lrcorner^{\top}$ & $28.7 \pm$ & $1.6-^{\top}$ \\
\hline \multicolumn{5}{|c|}{ Total cholesterol $(\mathrm{mg} / \mathrm{dl})$ : } \\
\hline Before & $31.8 \pm 6.0 \neg$ & $23.4 \pm 6.4\urcorner$ & $42.7 \pm$ & $: 13.4 \neg$ \\
\hline 12 wks after & $651.8 \pm 97.4^{-}$ & $559.6 \pm 83.2$ & $1274.0 \pm$ & $208.7-$ \\
\hline \multicolumn{5}{|c|}{ Triglyceride $(\mathrm{mg} / \mathrm{dl})$ : } \\
\hline Before & $92.2 \pm 8.1$ & $90.1 \pm 14.4$ & $104.2 \pm$ & 20.3 \\
\hline 12 wks after & $79.1 \pm 15.9$ & $61.7 \pm 11.4$ & $209.8 \pm$ & 71.6 \\
\hline
\end{tabular}

TABLE 2

The ratio of intima to intima plus media at the maximal and minimal sites of aortic wall thickness, with or without plaque formation

\begin{tabular}{|c|c|c|}
\hline & \multicolumn{2}{|c|}{ Ratio of intima/intima + media } \\
\hline & Maximal site & Minimal site \\
\hline \multicolumn{3}{|l|}{ Plaque $(+)$} \\
\hline Group A $(30 \mathrm{~Hz})$ & $0.111 \pm 0.049$ & $0.022 \pm 0.004$ \\
\hline Group B $(60 \mathrm{~Hz})$ & $0.074 \pm 0.060$ & $0.012 \pm 0.002$ \\
\hline Group C (controls) & $0.167 \pm 0.039$ & $0.014 \pm 0.002$ \\
\hline \multicolumn{3}{|l|}{ Plaque $(-)$} \\
\hline Group A $(30 \mathrm{~Hz})$ & $0.383 \pm 0.041$ & $0.132 \pm 0.067$ \\
\hline Group $\mathrm{B}(60 \mathrm{~Hz})$ & $0.364 \pm 0.044$ & $0.018 \pm 0.003$ \\
\hline Group C (controls) & $0.488 \pm 0.044$ & $0.097 \pm 0.048$ \\
\hline
\end{tabular}


TABLE 3

Metal concentrations in serum and aortic tissues

\begin{tabular}{|c|c|c|c|c|c|}
\hline Group & $\mathrm{n}$ & Calcium & Magnesium & Zinc & Copper \\
\hline \multicolumn{6}{|l|}{ Serum $(\mathrm{mg} / \mathrm{dl})$} \\
\hline A: $30 \mathrm{~Hz}$ & 6 & $13.5 \pm 0.2$ & $2.42 \pm 0.04$ & $0.199 \pm 0.009$ & $0.107 \pm 0.016$ \\
\hline B: $60 \mathrm{~Hz}$ & 6 & $13.7 \pm 0.3$ & $2.50 \pm 0.04$ & $0.204 \pm 0.009$ & $0.134 \pm 0.012$ \\
\hline $\mathrm{C}$ : controls & 5 & $13.4 \pm 0.2$ & $2.16 \pm 0.09$ & $0.174 \pm 0.016$ & $0.146 \pm 0.017$ \\
\hline \multicolumn{6}{|c|}{ Arotic tissues $(\mu \mathrm{g} / \mathrm{g}$ dry defatted weight $)$} \\
\hline A: $30 \mathrm{~Hz}$ & 6 & $1107 \pm 256$ & $200 \pm 10$ & $82.7 \pm 3.0$ & $3.10 \pm 0.21-$ \\
\hline $\mathrm{B}: 60 \mathrm{~Hz}$ & 6 & $1406 \pm 285$ & $220 \pm 18$ & $91.5 \pm 3.2$ & $3.38 \pm 0.82 *$ \\
\hline C: controls & 5 & $1414 \pm 505$ & $197 \pm 19$ & $89.8 \pm 2.5$ & $2.24 \pm 0.21-$ \\
\hline
\end{tabular}

mean \pm standard error; $* \mathrm{p}<0.05,{ }^{\dagger} \mathrm{p}<0.01$
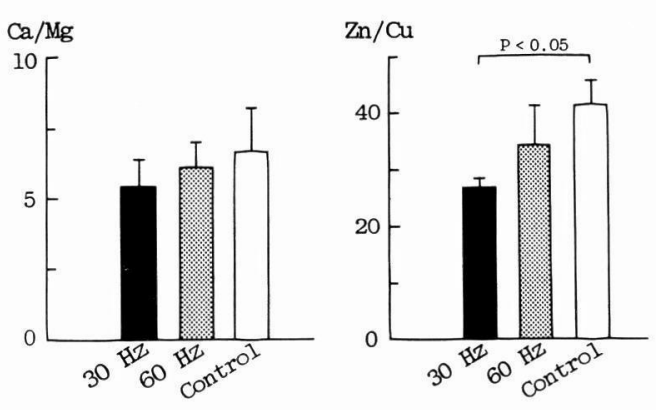

Fig. 1. Ratios of calcium/magnesium and zinc/copper in aortic tissues

Each column represents a mean \pm stand ard error.

measured at the maximal and minimal sites of wall thickness. The ratio of I to $\mathrm{I}+\mathrm{M}$ in each with or without plaque tended to be less in group B than in group A (Table 2).

\section{Metal concentrations.}

Table 3 compares the metal concentrations in the sera and aortic tissues from the 3 groups at the end of the experimental period. No significant differences were observed in the serum metal concentrations of the groups at the start of the experiments. By the 12 th week, the $\mathrm{Mg}$ concentrations in groups $\mathrm{A}$ and $\mathrm{B}$ were significantly higher than in the controls. The zinc $(\mathrm{Zn})$ and copper $(\mathrm{Cu})$ concentrations did not change, significantly, in any of the groups.

The $\mathrm{Ca}$ and $\mathrm{Zn}$ concentrations in aortic tissues from group A tended to be lower than in the other groups. The $\mathrm{Cu}$ concentration in group A was significantly higher than in the controls $(p<0.05)$. Figure 1 shows the ratios of $\mathrm{Ca}$ to $\mathrm{Mg}$ concentrations $(\mathrm{Ca} / \mathrm{Mg})$ and of $\mathrm{Zn}$ to $\mathrm{Cu}$ concentrations $(\mathrm{Zn} / \mathrm{Cu})$. The ratios of $\mathrm{Ca} / \mathrm{Mg}$ and $\mathrm{Zn} / \mathrm{Cu}$ in the vibration groups tended to be lower than in the controls. In the vibration groups, the value for group A tended to be lower than that for group $B$. The value for $\mathrm{Zn} / \mathrm{Cu}$ in group $\mathrm{A}$ was significantly different from the controls $(\mathbf{p}<0.05)$.

\section{Discussion}

The increases in serum total cholesterol and triglycerides induced by a cholesterolrich diet were suppressed by vibration. However, the body weight and hematocrit were not significantly changed by vibration. These findings indicate that suppression of the rate of increase in serum total cholesterol and triglycerides is not dependent on the cholesterol-rich food, 
but on the vibration. Vibration may play an important role in lipid metabolism.

Trace elements in aortic tissues could be directly or indirectly involved in the atherosclerotic process (Mertz, 1982; Aalbers and Houtman, 1985). Calcium concentrations are positively correlated to atherosclerosis, and magnesium concentrations are negatively correlated. The ratio of $\mathrm{Ca}$ to $\mathrm{Mg}$ should be proportional to the amount of plaque formation in the intima of the aorta. A high ratio of $\mathrm{Zn}$ to $\mathrm{Cu}$, due to a deficiency of $\mathrm{Cu}$, is positively related to the degree of atherosclerosis (Klevay, 1975); however $\mathrm{Cu}$ concentrations are not changed in the atherosclerotic aorta (Senapati et al. 1985). In the present study, a significantly higher ratio of $\mathrm{Zn}$ to $\mathrm{Cu}$, due to a deficiency of $\mathrm{Cu}$, was obtained in the controls as compared to the vibration groups. Accordingly, the ratios of $\mathrm{Zn}$ to $\mathrm{Cu}$ and $\mathrm{Ca}$ to $\mathrm{Mg}$ may be involved in the development of atherosclerosis.

The mechanism by which vibration suppresses the development of atherosclerosis is not clear. The rate of suppression in the development of atherosclerosis may depend on the frequency of vibration. The ratios of $\mathrm{Ca} / \mathrm{Mg}$ and $\mathrm{Zn} / \mathrm{Cu}$ in the aortic tissues were smaller at $30 \mathrm{~Hz}$ than at 60 $\mathrm{Hz}$, which were smaller than the controls. The area of plaque formation and the ratio of the intima to the intima plus media in the aortic walls were smaller at $60 \mathrm{~Hz}$ vibrations than at $30 \mathrm{~Hz}$. The vibration frequency influences blood flows which might result in the suppression of plaque formation. Vibrations at frequencies of $1-400$ $\mathrm{Hz}$ caused prompt reductions in the active forces of vascular smooth muscle in isolated preparations of rat portal vein and rabbit thoracic aorta (Ljung and Sivertsson, 1975). At all frequencies from 30 to 150 $\mathrm{Hz}$, contractions of isolated dog saphenous arteries were reduced significantly to approximately $60 \%$ of the controls (Lindbald et al. 1986). Skeletal muscle blood flow in the rabbit was augmented by vibration due to a considerable dilation of the re sistance vessels (Hudlicka and Wright, 1978). Acute exposure to vibration frequencies of 30 to $40 \mathrm{~Hz}$ produced vasodilation in the skin (Joyce et al. 1969). The myocardial blood flow was increased by vibrations at $120 \mathrm{~Hz}$ and decreased at 50 $\mathrm{Hz}$ (Matoba and Chiba, 1989). A hypothesis has been proposed that vibration exerts a direct action on the contractile process by causing an increased rate of detachment of actin-myosin cross-linkages (Ljung and Sivertsson, 1975). The changes of blood flow may be related to the suppression of plaque formation. In conclusion, whole-body vibration suppresses the development of atherosclerosis induced by a cholesterol-rich diet and also inhibits the increase of serum lipid concentrations. The degree of these changes may be dependent on the frequency of the vibration.

\section{References}

Aalbers, T. G. and Hovtman, J. P. W. (1985). Relationships between trace elements and atherosclerosis. Sci. Total Environ. 43, 255283.

Hudlicka, O. and Wright, A. (1978). The effect of vibration on blood flow in skeletal muscle in the rabbit. Clin. Sci. Mol. Med. 55, 471476.

Joyce, G. C., Rack, P. H. M. and Westbury, D. R. (1969). The mechanical properties of cat soleus muscle during controlled lengthening and shortening movements. J. Physiol (Lond), 204, 461-474.

Klevay, L. M. (1975). Coronary heart disease: the zinc/copper hypothesis. Am. J. Clin. Nutr. 28, 764-774.

Lindbald, L. E., Lorenz, R. R., Shepherd, J. T., et al. (1986). Effect of vibration on a canine cutaneous artery. Am. J. Physiol (Heart Circ Physiol). 19, H519-H523.

Ljung, B. and Sivertsson, R. (1975). Vibrationinduced inhibition of vascular smooth muscle contraction. Blood. Vessels. 12, 38-52.

Matoba, T. and Chiba, M. (1989). Responses of 
myocardial blood flows to whole-body vibration in the dog. Angiology, 40, 534-538.

MERTZ, W. (1982). Trace minerals and atherosclerosis. Fed. Proc. 41, 2807-2812.

Окі, М. and Матова, Т. (1987). Metal concentrations changed by vibration in the serum and aorta of rabbits. In Toxicology of Metals:
Clinical and Experimental Research eds. Brown, S.S. and Kodama, Y. pp.65-66. Chichester: Ellis Horwood Limited.

Senapati, A., Carlsson, L. K., Fletcher, C. D. M., Browes, N.L. and Thompson, R.P. H. (1985). Is tissue copper deficiency with aortic aneurysms? Br. J. Surg. 72, 352-353. 